\section{Medication, Dietary Supplement, and Alcohol and Tobacco Use in Sub-Elite Australian Rules Footballers - A Snapshot}

\section{Robert J. Douglas}

Sport Doctor, Honorary Medical Officer, Central District Football Club, Goodman Rd., Elizabeth South, South Australia

*Corresponding author: Robert J. Douglas, Sport Doctor, SportsmedSA Medical Division, 32 Payneham Rd., Stepney, Adelaide, South Australia and Honorary Medical Officer, Central District Football Club, Goodman Rd., Elizabeth South, South Australia 5112, Australia, Tel: 61883628111; Fax: 61883425118; Email: rabs01@hotmail.com

Copyright: @ 2014 Douglas RJ, et al. This is an open-access article distributed under the terms of the Creative Commons Attribution License, which permits unrestricted use, distribution, and reproduction in any medium, provided the original author and source are credited.

Received date: February 11, 2014; Accepted date: April 21, 2014; Published date: April 29, 2014

\begin{abstract}
Aim: Australian sport was rocked by the revelations of the Australian Crime Commission's report Organized Crime and Drugs in Sport. Although the primary focus of the report concerns the use of prohibited substances at elite level, the report also examined the possible effects of prohibited substance use at sub-elite levels. Little is known about the use of medications, dietary supplements, and alcohol and tobacco by Australian sub-elite athletes. This paper provides a 'snapshot' of use at a single sub-elite Australian Rules Football Club prior to the commencement of the 2012 South Australian football league season.
\end{abstract}

Design: Prospective survey of sub-elite footballers from a single South Australian club.

Method: Players were required to complete a medical questionnaire prior to the commencement of the 2012 SANFL season. As part of the questionnaire, players were provided with questions concerning the use of prescription medications, supplements, and alcohol and tobacco. Players that were included on the 'Senior Training Squad' were identified and their questionnaires used in the preparation of this article.

Results: Few players use prescribed medication, and a little over one-third of players take dietary supplements. Alcohol was the most consumed item, with $82 \%$ reporting some alcohol use. Daily tobacco use was almost nonexistent. There were no reports of the use of substances prohibited by the World Anti-Doping Agency (WADA).

Conclusions: Alcohol is the substance most used by players, with prescribed medication use almost entirely limited to asthma medications. Prohibited substance use is undetectable.

Keywords: Australian Rules football; Alcohol; Tobacco; Prohibited substances; WADA code; Medication

\section{Introduction}

The release of the Australian Crime Commission (ACC) report Organized Crime and Drugs in Sport [1] in February 2013, concerning the use of:

"New generation performance and image enhancing drugs...(and) ...their use in professional sport"

Is a cause for enormous concern in the Australian Football League (AFL) and the National Rugby League (NRL), and has sent shockwaves through the broader Australian sporting community. The ACC report also highlighted the possible use of banned substances by athletes in sub-elite competition, and described an investigation into the attempted importation of growth hormone releasing peptide- 6 (GhRP-6) by a rugby union player in a state club rugby competition.

The last AFL player to be banned for the deliberate use of a prohibited substance occurred in 1997 [2]. In sub-elite Australian Rules Football (ARF) State League competitions, three Western Australian Football League (WAFL) players have more recently received bans for the deliberate use of substances prohibited by the
Australian Sports Anti-Doping Authority (ASADA)- one player for the deliberate use of the anabolic steroid nandrolone, and one for the use of pseudoephedrine [3], and one player who was banned after testing positive to both nandrolone and the illicit substance cocaine [4].

Although sporting code and community concern surrounds deliberate use of these banned substances, the possibility also exist for accidental breach of the 'doping guidelines' by the ingestion of prohibited substances that are a constituent of otherwise legal supplements and medications. This most recently occurred in a Victorian Football League (VFL) player in 2012, following the use of the 'energy supplement' Hemo-Rage [5].

While there is no information at present to suggest that similar problems exist at sub-elite South Australian National Football League (SANFL) level, the possibility always exists of clandestine use, with all the associated difficulties in detection and identification of use.

This article examines the use of pharmaceutical medications, dietary supplements, and alcohol and tobacco use in a single sub-elite ARF Club prior to the commencement of the 2012 season of the SANFL, and attempts to address the lack of knowledge of these issues at the sub-elite ARF level. 


\section{Method}

Sub-elite players at the Club were required to complete a medical questionnaire prior to the commencement of the 2012 SANFL season.As part of the medical questionnaire, players were provided with a series of questions concerning the use of prescription medications, supplements, and alcohol and tobacco usage (Appendix A). Although the data from the questionnaire was not collected in an anonymous manner, all players were asked to provide written, informed consent for the use of their de-identified data. No data was collected in relation to products such as 'electrolyte sporting drinks' that are provided to players by the Club at the completion of each game.

Players that were included on the 'Senior Training Squad' were identified and their questionnaires used in the writing of the article. Players that were associated with the sub-elite Club but were also on the 'Playing List' of either of the two Adelaide-based AFL Clubs (Adelaide Crows and Port Adelaide Power) were excluded from the analysis, as their medical care is under the supervision of the Medical teams at their respective AFL Clubs.

Formal Ethics Committee approval for the study was not sought as the study is (i) low risk; (ii) collected data was anonymously compiled; and (iii) written consent was obtained from all participants prior to collection of the data.

\section{Results}

The 'Senior Training Squad' comprised 47 sub-elite players. Of these, four (9.5\%) withheld consent to use collected data.

\begin{tabular}{|l|l|l|}
\hline & Agent & $\mathbf{n}(\%)(\mathbf{N}=38)$ \\
\hline Medication & Salbutamol inhaler & $5(13.2)$ \\
\hline & Inhaled corticosteroidA & $1(2.6)$ \\
\hline & NSAID & $1(2.6)$ \\
\hline SupplementsB & Fish oil & $11(28.9)$ \\
\hline & Protein powders & $9(23.6)$ \\
\hline & Magnesium & $2(5.2)$ \\
\hline & Multivitamin capsules & $2(5.2)$ \\
\hline Alcohol & L-carnitine & $1(2.6)$ \\
\hline & Vitamin C & $1(2.6)$ \\
\hline & Never & $7(18.4)$ \\
\hline & Rare & $11(28.9)$ \\
\hline $\begin{array}{l}\text { A Single respondent using regular 'preventor' and salbutamol } \\
\text { supplements }\end{array}$ & Once/week used supplements. Some respondents were using 2 or more \\
\hline
\end{tabular}

Table 1. Summary of regular medication, supplement, and alcohol use amongst sub-elite ARF players
A further five players who were eligible to play for the Club but were contracted to one of the two Adelaide-based AFL Clubs (Adelaide Crows 4, Port Adelaide Power 1) also were not included in the analysis. Thus, the details of 38 players were available for analysis. They ranged in age from 17 to 34 years. No data was collected on educational achievement, or employment status.

Six players reported the use of a regular medication-five of these (13\%) were for the treatment of asthma, and only one player $(2.6 \%)$ required the medication combination of an inhaled corticosteroid and inhaled salbutamol (Table 1). Fourteen players (37\%) reported supplement use. None of these supplements were prohibited under the 2012 World Anti-Doping Agency (WADA) regulations. Six players used more than one supplement (Table 1).

Alcohol was the most consumed item. The majority of players reported using alcohol once per week $(14 / 38,37 \%)$, while a large number $(11 / 38,29 \%)$ reported drinking alcohol rarely. From the provided information, only one player's alcohol use could be determined to be 'hazardous'. Unexpectedly, seven players (18\%) abstained from alcohol (Table 1). Only one of these seven players was a minor. Only one player smoked, with an estimated tobacco use calculated to be one packet/fortnight. No player reported recreational drug use, and there was no reported use of substances prohibited under WADA 2012 regulations.

\section{Discussion}

This study found that regular, prescribed medication use centred almost exclusively on the treatment of asthma, a finding not previously reported in articles of this type. Although Falvey et al. [7] have reported that the prevalence of asthma and airway responsiveness in the Irish National Rugby union team is similar to that of this sub-elite SANFL Club, Tscholl, Junge and Dvorak [8] found that only $1.4 \%$ of players at the 2002 and 2006 FIFA (Soccer) World Cup were using an inhaled 2-agonist, and that $1.6 \%$ were using an inhaled corticosteroid. Although there are several possible reasons for the large difference in the prevalence of airway disease and the use of asthma medications, they will not be discussed in this paper.

Alcohol was the substance most often used by the playing group. Data (2004-05) from the Australian Bureau of Statistics (ABS) reports that $10 \%$ of the Australian adult population abstains from alcohol, and that $13 \%$ of adult males consume alcohol in 'at risk' amounts [9]. This paper's findings of $18 \%$ abstention and $2.6 \%$ 'at risk' consumption are significantly different from that expected in an age-matched cohort. Binge drinking, while not explicitly investigated in this paper would appear from the results to be the most frequent 'at risk' alcohol behaviour, mirroring ABS reported levels of binge drinking of 48\% [9].

Only one player was found to be a smoker, but at a very low level of consumption. This is in marked contrast to the reported adult Australian male daily smoking rate of $16.4 \%$ (2010 data) [10].

The study found that only a minority of sub-elite ARF players use dietary supplements (DS). This contrasts to other Australian studies detailing supplement use by $>90 \%$ of elite swimmers [11], and of $>85 \%$ of elite team sport athletes at the Western Australian Institute of Sport (WAIS) [12]. International studies of DS use have found a similar incidence $[13,14]$. These findings are even more surprising as it is known that men are more likely to consume DS than women [15]. It is possible that the observed use of DS in sub-elite ARF Clubs has 
changed over time, but in the absence of any published data on this topic, is only speculation.

Although there is no evidence from this study to suggest that there exists a problem at this sub-elite SANFL football club with the use of prohibited substances, the use of other (legal) supplements opens the possibility of inadvertent use of prohibited substances, or the use of these legal substances as a 'stepping stone' to banned substance usage. Backhouse, Whitaker and Petroczi [16] suggest that athletes that engage in the use of legal performance-enhancing practices appear to embody an 'at risk' group for transition to the use of illegal doping. Diehl et al. [17] found that amongst elite adolescent German athletes that the main source of information concerning DS and their use emanates from their coaches, but that parents were the main source of DS supply. Other authors $[12,13]$ have found that large numbers of athletes taking DS do not have an adequate knowledge of the ingredients of the supplements, nor do they appreciate the benefits and risks associated with their use. Given that there is a real risk for an otherwise legal DS to contain an unlabelled banned ingredient [18], the unsupervised use of DS may increase the risk of inadvertently testing positive for a banned substance.

Several limitations can be identified in this study. Firstly, the data set in this study is small, as membership of the Senior Squad is necessarily restricted to those players capable of performing at subelite ARF standard. Second, although the medical questionnaires were for the exclusive use of the medical staff of the Club, and the collected data was de-identified for the purposes of research, the questionnaire was not anonymous, and players may not have been entirely frank in their answers. That four player's withheld consent to use data may reflect a greater usage of alcohol, tobacco and supplements than they are willing to acknowledge. Similarly, given that $6 / 38$ (15.8\%) of players failed to report a specific alcohol usage, the collection of data as to rate of alcohol and tobacco use may be underestimated for similar reasons, but the reported rate may also reflect a known bias in the collection of data of this type [19].

Third, the medical questionnaire did not take into account medications used during the course of the season (such as NSAIDs) for the management and treatment of injuries and illnesses, which appears to fluctuate with match patterns [8].

Finally, by their very illegality, the use of supplements and recreational drugs prohibited under WADA regulations are kept secret, so this study may not be an accurate reflection of actual usage, however strict self-regulation within the Club, and within the player peer groups, appears reduce this possibility.

Although there are problems with the identification of users of prohibited substances, the deliberate use of performance-enhancing substances appears to be exceedingly rare. At elite levels, it has been suggested that recreational drugs may be more commonly used [20], and it is possible that this is mirrored in Australian sport. The process of data collection in this survey was insufficient to test this theory.

\section{Conclusion}

This paper has demonstrated that the major substance used by subelite ARF players mirrors that of broader society, alcohol. Tobacco use is almost non-existent. Whilst dietary supplements are ingested by some sub-elite ARF players, the majority of players do not, and further research is required to determine the reasons for the significantly different levels of supplement use by ARF players compared with elite athletes in other sports, as well as their real impact upon ARF performance.

It is the Author's opinion that potential problems arising from the use of DS may be prevented by the fostering of close relationships of players with the medical, paramedical, and fitness and training staff of individual clubs, allowing open disclosure of the use of any substance. Finally, the author strongly encourages the governing bodies of Australian sport to continue to provide education to elite and sub-elite athletes on the dangers of prohibited substance use, and assists these athletes in the identification of possible prohibited substances as ingredients of otherwise legal dietary supplements.

\section{Acknowledgements}

The author wishes to thank Dr. Tonia Mezzini for her assistance with the preparation of the manuscript, and to all players involved in the provision of data.

\section{References}

1. Australian Crime Commission (2012) Organised Crime and Drugs in Sport.

2. http://www.adelaidenow.com.au/sport/afl/justin-charles-tells-of-drugdisgrace/story-e6freck3-1226082383335

3. http://www.theage.com.au/sport/wa-football/no-drugs-epidemicwafl-20110613-1g05h.html

4. http://www.abc.net.au/news/2011-10-17/wafl-player-cops-drug-ban/ 3575690

5. http://www.heraldsun.com.au/sport/afl/drug-suspension-for-frankstonplayer/story-fn53khop-1226365539664

6. World Anti-Doping Agency (2012) List of Prohibited Substances and Methods.

7. Falvey EC, McCarthy C, O'Connor TM, Shanahan F, Molloy MG, et al. (2010) Exercise-induced bronchoconstriction and exercise testing in an international rugby union team. Thorax 65: 843-844.

8. Tscholl P, Junge A, Dvorak J (2008) The use of medication and nutritional supplements during FIFA World Cups 2002 and 2006. Br J Sports Med 42: 725-730.

9. Australian Bureau of Statistics (2006) Alcohol Consumption in Australia: A Snapshot, 2004-05.

10. Australian Institute of Health and Welfare (2011) 2010 National Drug Strategy Household Survey report. Drug statistics series no. 25.

11. Baylis A, Cameron-Smith D, Burke LM (2001) Inadvertent doping through supplement use by athletes: assessment and management of the risk in Australia. Int J Sport NutrExercMetab 11: 365-383.

12. Dascombe BJ, Karunaratna M, Cartoon J, Fergie B, Goodman C (2010) Nutritional supplementation habits and perceptions of elite athletes within a state-based sporting institute. J Sci Med Sport 13: 274-280.

13. Maughan RJ, Depiesse F, Geyer H; International Association of Athletics Federations (2007) The use of dietary supplements by athletes. J Sports Sci 25 Suppl 1: S103-113.

14. Tscholl P, Alonso JM, Dollé G, Junge A, Dvorak J (2010) The use of drugs and nutritional supplements in top-level track and field athletes. Am J Sports Med 38: 133-140.

15. Karimian J, Esfahani PS (2011) Supplement consumption in body builder athletes. J Res Med Sci 16: 1347-1353.

16. Backhouse SH, Whitaker L, Petróczi A (2013) Gateway to doping? Supplement use in the context of preferred competitive situations, doping attitude, beliefs, and norms. Scand J Med Sci Sports 23: 244-252.

17. Diehl K, Thiel A, Zipfel S, Mayer J, Schnell A, et al. (2012) Elite adolescent athletes' use of dietary supplements: characteristics, opinions, and sources of supply and information. Int J Sport NutrExercMetab 22: $165-174$. 
Citation: Douglas RJ (2014) Medication, Dietary Supplement, and Alcohol and Tobacco Use in Sub-Elite Australian Rules Footballers - A Snapshot. J Sports Med Doping Stud 4: 136. doi:10.4172/2161-0673.1000136

Page 4 of 4

18. Burke LM (2000) Positive drug tests from supplements. Sport science 4.

19. Midanik L (1982) The validity of self-reported alcohol consumption and alcohol problems: a literature review. Br J Addict 77: 357-382.
20. Waddington I, Malcolm D, Roderick M, Naik R (2005) Drug use in English professional football. Br J Sports Med 39: e18. 